\title{
Proceso de terapia existencial de artes expresivas
}

Expressive arts existential therapy process

José Miguel Mayorga González

Natalia Roció Méndez Pérez²

RECIBIDO: 9 DE ABRIL DE 2020

ACEPTADO: 5 DE JUNIO DE 2020

\section{RESUMEN}

El estudio se orientó a comprender el proceso de la Terapia Existencial de Artes Expresivas, explorando a partir de un análisis documental temas como la imaginación, la experiencia, las modalidades de expresión, la experimentación pobre, todo lo anterior, desde una mirada fenomenológico-existencial, centrada en lograr acompañar al consultante a explorar y comprender la existencia como un

\footnotetext{
' Doctor en Pensamiento Complejo, Maestría en Intervención Social, Psicólogo, Semillero de Investigación Multiverso Social, Corporación Universitaria Minuto de Dios, Rectoría Cundinamarca, Colombia; info@cafexistencial.com, ORCID: https://orcid.org/0000-0002-0326-4824

Google Scholar: https://scholar.google.es/citations?user=7HeQZSMAAAAJ\&hl=es

2 Estudiante de Licenciatura en Pedagogía Infantil, Semillero de Investigación Multiverso Social, Corporación Universitaria Minuto de Dios, Rectoría Cundinamarca; mnatalia2612@gmail.com, ORCID: https://orcid.org/0000-0002-9477-1337

Google Scholar: https://scholar.google.com/citations?hl=en\&user=McL5JKUAAAAJ
}

Socialium, revista científica de Ciencias Sociales, Vol 4 - No. 2, julio - diciembre 2020, pág. 299-316. 


\title{
300
}

continuo y complejo misterio relacional, que requiere ser reflexionado constantemente, para asumir la vida con apropiación y responsabilidad.

Palabras clave: fenomenología, modalidades de la imaginación, imaginación, sentido de vida, experiencia sentida

\begin{abstract}
The following article focuses on understanding the process of Existential Therapy of Expressive Arts, exploring from a documentary analysis topics such as imagination, experience, modes of expression, poor experimentation, all of the above, from a phenomenological perspectiveexistential, focused on helping the client to explore and understand existence as a continuous and complex relational mystery, which requires constant reflection, to assume life with ownership and responsibility.
\end{abstract}

Keywords: phenomenology, modes of imagination, imagination, meaning of life, felt experience

\section{Introducción}

El estudio buscó comprender ¿̇cómo es el proceso de la Terapia Existencial de Artes Expresivas (TEAE) en el desarrollo humano y el cambio social? Para responder esta pregunta, es importante indagar y describir las bases teóricas y prácticas de la misma, desde una perspectiva fenomenológica-existencial; analizando los supuestos mismos del desarrollo de la Terapia Existencial de Artes Expresivas (TEAE); logrando como objetivo comprender este proceso en el desarrollo humano y el cambio social. A partir de lo anterior, esta investigación constará de tres apartados, 1. Bases teóricas y prácticas de la Terapia Existencial de Artes Expresivas (TEAE); 2. Profundización de los supuestos de la propuesta 3. Reflexión en torno a la propuesta, el desarrollo humano y el cambio social.

Autores como Frankl (1984 y 1962), Längle (2009), Laing (1977) y Mayorga-González (2011, 2016, 2019) parten del estudio existencial del ser humano, dando las bases antropológicas y filosóficas de la comprensión del sujeto como un ser relacional en situación (Mayorga-González, 2016), por ello es de suma importancia, profundizar en 
sus obras, para fortalecer las bases teóricas de la Terapia Existencial de Artes Expresivas (TEAE).

\section{Bases teóricas y prácticas de la Terapia Existencial de Artes Expresivas (TEAE): Sentido de la vida y Mirada existencial}

Para encontrar sentido a la vida, se debe reconocer el significado de ella, ya que este no puede ser identificado por persona ajena, sino solo se encuentra en la singularidad del sujeto. Frankl (1962) afirma "el sentido de la vida en cada persona es único y cada quien debe encontrar que lo motiva a lograr alcanzar la satisfacción de su propia voluntad de sentido" (p.16).

Partiendo de lo anterior, surge la pregunta, ¿̇qué es el sentido de la vida? para Frankl (1962) el sentido de la vida, está en hallar un propósito, en asumir una responsabilidad para consigo mismo y con su entorno. Además, propone una reflexión en cuanto al sentido pues afirma que "el ser humano no tiene la obligación de definir el sentido de la vida en términos universales. Cada uno de nosotros lo haremos a nuestra manera, partiendo de nosotros mismos, desde nuestro potencial y experiencias, descubriéndonos en nuestro día a día". (Sabater Valeria, 2019, p.59).

Por otra parte, Alfried Längle (2000) afirma que sentido de la vida desde una perspectiva existencial tiene dos sustentos en la toma de decisiones que es la libertad y la responsabilidad la cual afirma, a diferencia de Viktor Frankl, que la existencia no es individual si no es del contexto, lo cual implica una constante relación del sujeto con el mundo, los otros, sí mismo y la situación que lo lleva constantemente a decidir y responder ante la vida. Asi,

Desde una perspectiva existencial, la realización de la existencia humana se caracteriza por la toma de decisiones (libertad, responsabilidad). Mientras que la existencia de un individuo es experimentada únicamente de mi pertenencia, el proceso de llegar a una decisión está muy influenciado por el contexto del mundo particular de esa persona" (Längle, 2007, p. 8).

Puede afirmarse, de acuerdo con los autores nombrados, que el sentido de la vida es subjetivo en cuanto que no hay un sentido para todos los hombres, ya que no es posible decidir por si mismo, siguiendo a Längle (2009), la libertad en el contexto está condicionada de acuerdo con las necesidades de cada persona y sus relaciones. 


\section{2}

Asimismo, Frankl (1962, 1984, 1988, 1994, 1995 y 2001) plantea que esta libertad requiere el encuentro con valores que den propósito al actuar, es decir, a responder a la vida con habilidad, así, plantea tres categorías principales de valores o posibilidades que permiten el hallazgo de sentido: los valores de creación, experiencia y actitud.

Los valores creativos, son aquellos en los cuales se implica elaborar un proyecto, para así poder llevarse a cabo y que de manera constructiva se alimente así mismo, como el proyecto de vida, la creación, elaboración para sí mismo o el mundo. Castro (2010) señala que son los que el humano realiza, ya sea el trabajo, un pasatiempo, su profesión, entre otros. Modificar o cambiar algo son las palabras claves en cuanto a valores creativos se refiere.

Los segundos valores son los experienciales, aquellos que permiten concientizar las experiencias vividas, por ejemplo, la naturaleza o el amar sin intención de recibir algo a cambio, la satisfacción que da el haber entregado algo como recompensa a nuestro propio sentido. Castro (2010) quien explica que están relacionados al vivir la belleza, el arte, una experiencia religiosa, el amor, el contacto con la naturaleza, con el otro, y con la verdad, podríamos suponer que es el arte de disfrutar de la bondad, la belleza y la verdad.

Por último, los valores actitudinales siendo estos considerados como los más importante de los valores; afirma Frankl (1990) que es el valor más supremo, siendo el de más profundo alcance entre los valores de creación y de experiencia. Son aquellos valores que influyen de manera suprema en su ser, por ejemplo, la compasión, el sentido del humor y el sufrimiento, aquellos sentimientos que se consideran inevitable e imposibles de resolver (Frankl,1984). Frankl les concede un grado de relevancia a los valores actitudinales ya que este no puede ser influenciados, este valor es auténtico, presenciando una situación límite, no se busca o planifica, es espontáneo para que se decida como vivir en aquel momento de crisis.

El sentido de la vida se convierte en la posibilidad de cambio ante situaciones límites, o por el contrario la posibilidad de contemplación o de acción, pero desde una mirada relacional o compleja, este encuentro con el sentido y sus valores requiere la interacción constante del sujeto como ser-en-el-mundo y ser-con-los-otros. 


\section{Fenomenología social desde la dinámica relacional}

Laing, (1983), señala:

Yo te veo y tú me ves. Yo te experimento y tú me experimentas. Yo veo tu comportamiento y tú ves mi comportamiento. Pero yo no veo, no he visto ni veré nunca tu experiencia de mí. Del mismo modo que tú tampoco puedes ver mi experiencia de ti. Mi experiencia de ti no está "dentro" de mí". (p.16).

A partir de lo anterior, el juego de relación del sujeto con los otros es la interexperiencia, es decir un intercambio dialógico constante (Mayorga-González 2018), en donde lo único que percibe el sujeto del otro es su comportamiento como forma de confirmación, a partir de esto Laing (1974), habla sobre los modos de experiencia interpersonal los cuales son la fantasía de la experiencia, fantasía y comunicación, que permiten al sujeto acercarse a la relacionalidad con el mundo, los otros, sí mismo y las situaciones.

La fantasía debe ser vista desde lo fenomenológico, para que las personas le den un significado existencial, Para Modernell (2019)

No puedo experimentar tu experiencia, de cómo se vivencian las experiencias del ser humano en el mundo, en un mundo que incluye a otros seres humanos. Para estudiar el comportamiento de las personas, primeramente, es necesario conocerlas. Tú no puedes experimentar mi experiencia. Ambos somos hombres invisibles. (p.4).

Laing (1962) explica la fantasía y comunicación como la importancia que tiene nuestras experiencias del comportamiento consigo mismo y con los demás. Laing (1961) además, precisa que la fantasía cumple una importante función; la sociedad vive por medio de la fantasía, los lazos de unión cubren una necesidad que únicamente se puede dar mediante ella, por ejemplo, el sentimiento de lazos fraternales de familia, está basado en una fantasía que entre los miembros comparten, a esto Stolorow y Atwood (2004) los señala como principios organizadores, los cuales van generando patrones recurrentes de relación en los diferentes contextos, es decir, comportamientos.

La fantasía son aquellos principios que van organizando nuestra realidad y van siendo aprobados en la relación con el otro, permitiendo de alguna manera a través de la imaginación ser plasmados como formas, tamaños o inclusive la propia modificación 


\section{4}

de estos principios organizadores desde un ejercicio creativo y expresivo que parte de la imaginación, que a su vez parte del hecho de su fantasía.

De acuerdo con lo anterior, la fenomenología social se encarga de estudiar la Interexperiencias, las cuales consisten en relacionar mi experiencia del comportamiento del otro con la experiencia que tiene el otro de mi comportamiento, incluyendo la propia de la fantasía. ¿Pero cómo la fenomenología y la dinámica relacional comprenden las experiencias relacionales?

Mayorga-González (2016) refiere que la dinámica relacional "permite no solo comprender la experiencia relacional sino como se van creando las diferentes problemáticas y soluciones psicosociales" (p.11). Es aquella relación que tenemos constantemente entre sí mismo y nuestro entorno social, lo que lleva a asumir roles y patrones recurrentes, en la interacción con otros y orientados a responder ante los desafíos y tareas cotidianas.

Asimismo, la dinámica relacional es la interacción que se da en diferentes situaciones con el otro, es decir, son los valores, el cuerpo y las emociones que permite apropiarse de la interacción en sí mismo y con el otro para poder tener sentido a su existencia. Mayorga-González (2018) afirma que "es la capacidad de asumir una actitud libre y responsable frente a la existencia, logrando gestionar los procesos afectivos, cooperar en el reconocimiento de la experiencia del otro y asumir la propia responsabilidad de existir" (p.11). En otras palabras, es la interacción que tenemos entre nuestro yo personal o sí-mismo y nuestro yo social o para- otros.

En la dinámica relacional las interacciones de lo personal-relacional se va generando desde diferentes aspectos que se van relacionando; aspectos personales como la receptividad, la impresión, la comprensión, la toma de posición, la capacidad de respuesta y la expresión (Kwee y Längle, 2013) y aspectos sociales como el rol, las máscaras y el otro (Mayorga, 2015 y Mayorga y Herrera, 2016), toda esta interacción se va dando en espacios contextuales en donde se presentan diferentes pruebas y soportes (Martuccelli, 2002) y que van conformando la dinámica relacional.

\section{Las modalidades de la imaginación y el teatro pobre como estrategia}


La imaginación son aquellas imágenes, historias o recuerdos, que creamos en nuestra mente y la asociamos con lo que nos da la realidad, con formas, tamaños, entre otros. Knill (2009) precisa que "muchas experiencias mentales creadas o percibidas visualmente se van almacenando en nuestro cerebro en forma de imágenes como ocurre con los sueños, algunos recuerdos, o fantasías son producidas por la imaginación" (p.23)

Al hablar de fantasía como una manifestación de la experiencia, es decir, como una manifestación del relato subjetivo del individuo y del relato relacional, está fantasía permite ir constituyendo principios organizadores que van segmentado la dinámica relacional de la vida cotidiana. En una propuesta de artes expresivas está experiencia es importante cristalizarla a través de las diferentes modalidades de la imaginación, dado que permite de alguna manera evocar, relatar o crear, llevando al individuo a la posibilidad de cambio y de encuentro con el sentido de la vida logrando movilizar las capacidades de autodistanciamiento y autotrascendencia.

Las cuales Frankl plantea son las capacidades de monitorearse o distanciarse. Mayorga-González (2020) las señala como de gestionar los propios procesos personales, y la capacidad de autotrascendencia, la cual, es la capacidad de salir de uno mismo hacia el otro, hacia algo más allá, para Mayorga-González (2020) ser sustento ser soporte en la relación con los otros.

Una terapia existencial de artes expresivas requiere tanto el uso de la imaginación como el actuar para descubrir, clarificar la experiencia, así como de herramientas corporales, gestuales o vocales, remembrando la experimentación pobre como recurso propio de las terapias de artes expresivas.

Para lograr esto es importante ampliar el mundo a través de la generación de ambientes seguros y de aperturas los cuales son espacios donde la persona percibe, en terapia, reconocimiento por sus acciones, oportunidad para desarrollarse y el cuidado ante su intimidad. De esta manera tanto el encuentro terapéutico como la relación y la percepción del consultante con el terapeuta, se mantendrá desde una relación experimental y sincrónica donde se dará paso al juego y el intercambio de posiciones relacionales, logrando experimentar el encuentro con la propia existencia. 


\section{6}

Es por eso, que Ricoeur (2000) propone tres conceptos de imaginación, el primero es la evocación de cosas ausentes pero existentes en otro lugar, el segundo los cuentos, los relatos y las imágenes que tiene una existencia física propia pero su función es ponerse en lugar de otra cosa y el tercero es la evocación de cosas inexistentes lo cual lo denomina ficción.

A partir del ejercicio de La imaginación, y de sus tres expresiones como la evocación la imagen y el relato o la ficción, se presenta las modalidades de la imaginación, es decir a través de un ejercicio sensitivo o estético, esta imaginación permite generar, imágenes, movimientos, actos, palabras, sonidos y ritmos, los cuales se van a cristalizar a través de diferentes modos artísticos como el poema, la danza, el teatro, el juego, entre otros.

\section{Experiencia Sentida}

La experiencia sentida es la sensibilidad del terapeuta ante la propia manifestación emocional que ocultamente busca ser expresada y que requiere de un impulso y un acto que lleve al consultante hacia manifestación de la experiencia, a través de diferentes modalidades de la imaginación que se puede describir como esa sensibilidad y resonancia del terapeuta hacia el consultante, hacia el contenido existencial del otro y del cual, el terapeuta identifica desde la propia <epoje> que no hace parte de la experiencia directa, sino que está sensibilidad se presenta justo en el encuentro con el otro.

Se requiere entonces que el terapeuta antes de iniciar su acompañamiento o su encuentro terapéutico con el consultante, descubra sus supuestos, su perspectiva de mundo o sus prejuicios (no para ser una tabula rasa, sino para poder permitirse ser sensible a la resonancia del contenido existencial del otro) cuando este contenido llega, cuando la experiencia es narrada y cuando el consultante descubre los nudos y enredos que existen en esa experiencia, pero que a través de la palabra no se puede desarrollar, puede utilizar la estrategia de la terapia existencial de artes expresivas, para enfocar esa experiencia a través de la imaginación, cristalizándola en un producto, un producto que en sí mismo es el sujeto. 


\section{La exploración pobre como herramienta de cristalización.}

Jerzy Grotowski crea "Teatro pobre", un teatro que puede vivir sin vestuarios, sin maquillaje, sin guion, sin ambientación, sin efectos de sonido, entre otros. Grotowski (2009) precisa que "abandonamos el maquillaje, las narices postizas, los estómagos absolutados falsamente, todo aquello que el actor utiliza en su vestidor antes de la presentación" (p.4) es decir, solo queda el sujeto con su existencia reflejada en su cuerpo.

Existe un factor fundamental que sin él no existiría la experiencia de cristalización y es la relación que se debe trasmitir entre el sujeto y su propia dinámica relacional. El sujeto trasmite mediante el uso controlado de sus gestos y su expresión corporal sus propias experiencias, esto siempre ha sido la herramienta principal del actor, no es necesario tener tantas cosas, se puede crear música desde el propio cuerpo, ya sea por medio de golpecillos o con la voz, el cuerpo del actor ilumina el escenario el <encuentro terapéutico>.

Así, Grotowski precisa que "escoger un impulso emocional, llorar, por ejemplo y transferirlo a una parte especial del cuerpo, al cual hay que darle expresión (Grotowski. J,1965, p.77). por medio de las modalidades de la imaginación sea para evocar, para transformar o para crear la experiencia de la dinámica relacional.

\section{Método}

Se realizó la utilización del método bibliográfico a partir de la fuente de recursos verbales o directos, así como indirectos y recursos de literatura (informes técnicos, artículos científicos, folletos, presentaciones, etc.) y publicaciones secundarias (como reseñas, referencias de revistas y periódicos).

Además de lo anterior, se aplicaron de forma segundaria métodos y técnicas de investigación cualitativa tales como: observación participante, análisis de contenido, lectura e interpretación de textos. A través de los métodos utilizados y los métodos aplicados, se obtuvieron los resultados esperados. 


\section{8}

\section{Resultados y discusión}

\section{¿Qué es la Terapia Existencial de Artes Expresivas?}

A partir de lo anterior, la Terapia Existencial de Artes Expresivas es una estrategia creada con el objetivo principal de permitir a la persona el desarrollo integral orientado a la afirmación y responsabilidad de la vida desde contextos analógicos y actitudes espontáneas. (Mayorga-González, 2014). Este desarrollo integral está orientada a la exploración de la dinámica relacional y el despliegue de las capacidades existenciales, a través del uso de estrategias simbólicas y espontaneas que parten de la experimentación pobre, la exploración fenomenológica y el encuentro existencial, más allá del instrumental y orientado hacia el desarrollo humano y el cambio social.

Pero ¿̇Cómo se comprende el desarrollo humano desde una perspectiva fenomenológico-existencial? Según Mayorga-González (2014)

"El bienestar existencial es un estado o sensación de plenitud, es decir, de una vida llena de sentido en la situación concreta y que se da en la reflexión de la persona de su vivencia" (Mayorga-González, 2014)

Es decir, el desarrollo humano implica la sensación de plenitud, que implica percibir la posibilidad con más valor en las situaciones y que solo se da a través de la reflexión constante, cuando se logra llegar al encuentro del sentido, el sujeto también tiene la posibilidad de transformar su propia relación con el mundo, con los otros y con la situación.

Con lo anterior, se vuelve de suma importancia que las personas que llegan al bienestar existencial (desarrollo humano) transfieran esta sensación a través de un ambiente seguro y de apertura, lo que implica un cambio de las condiciones iniciales, es lograr una transformación social. A partir de lo anterior la Terapia Existencial de Artes Expresivas, para lograr el desarrollo y el cambio requiere trabajar en el encuentro terapéutico contextos analógicos.

\section{Contextos analógicos}

Los contextos analógicos son situaciones que se comparan con las vivenciadas por las personas y que permiten el percatarse de los procesos internos y posibilidades 
externas, acercarse a lo propio y lo posible y asumir una posición personal y una actitud espontáneamente responsables. Estas situaciones permiten el percatarse de los procesos internos y posibilidades externas, acercarse a lo propio y lo posible y asumir una posición personal y una actitud responsable.

Estas actitudes espontáneas empleadas en la Terapia Existencial de Artes Expresivas se utilizan

Cuando la persona percibe los contextos y empieza a jugar con ellos, inicia un trabajo de improvisación, promoviendo actitudes espontáneas que movilizan las capacidades espirituales. Estas actitudes se expresan cancelando la posibilidad de hablar, pero expandiendo las demás categorías de la voz y el acompañamiento del movimiento". (Mayorga-González, 2014, p.14).

El trabajo de Terapia Existencial de Artes Expresivas (TEAE), se centra en crear situaciones en donde los participantes interactúen activa y espontáneamente, expresando por medio de la voz y el movimiento la vivencia que le genera molestia en su vivir; descubriendo a través del trabajo exploratorio y expresivo el campo emocional en el que se encuentra.

La voz no es el único canal de comunicación los gestos, los gruñidos el grito, el quejido, la risa, la melodía, también trasmiten un mensaje, también son un medio de comunicación, como lo precisa Cerezo (2013) "Profundizar el nivel de conciencia del cuerpo y añadir la emisión del sonido, como forma de potenciar aún más la expresión de sensaciones y emociones" (Mayorga-González, 2014).

Mayorga-González (2014) propone momentos en el proceso creativo, como lo son explorar, experimentar y expresar. En el momento de Explorar los participantes juegan, interactuando con el exterior, (el grupo, el espacio, el material, la experiencia de los demás), en este espacio las emociones son el protagonista. El siguiente momento se nombra Experimentar, el grupo se abre totalmente al diálogo y el intercambio de experiencias son la vivencia auténtica. El último momento lo denominó Expresar, en este momento, el líder del grupo permite que cada integrante del grupo deje fluir sus sentimientos y se integre a su propio ser.

El proceso creativo debe permitir que la imaginación se haga sensible a través de diferentes modalidades (Intermodalidad) en un plano espontaneo y creativo 


\section{0}

(Descentralización) logrando plasmar lo propio y gamas de posibilidades a través del juego (Cristalización) desde un constante acto de hacer (Poiesis).

\section{Hacia la Poiesis}

Mayorga-Gonzalez (2016) afirma referente a la Poiesis que

Se puede por ende comprender que la acción es antes que la palabra, es decir que existir es antes que pensar; el sujeto esta-ahí y luego va reflexionándose hacia un serahí, pero esta reflexión no abarca toda la vivencia del sujeto, sino que aborda tan solo una perspectiva que se va argumentando de la cultura $u$ otras experiencias y busca anticiparse o proyectarse a nuevas situaciones relacionales. la perspectiva de esa experiencia abarca constructos (relatos) del otro, de sí mismo y del nosotros, estos constructos hacen que la persona separe entre la estructura y la vinculación en la situación, es decir entre lo objetivo y subjetivo de esta. (p.51).

En la construcción de la experiencia está orientada como lo indica su nombre a la experiencia que confirma la vida a la proyección de futuros modos de actuar ante los continuos cambios que tiene la vida. A partir de ello el constructo del otro parte de aquello que el individuo o la persona tiene experiencia con su entorno, como la sociedad, medio ambiente, virus, entre otros. En el constructo de sí mismo, son todas las percepciones que se tiene con sí mismo por ejemplo los sentimientos, creencias, entre otros. El constructo del nosotros es aquella relación o vinculo que se adquiere de forma autentica desde diferentes roles como dominación, sumisión

De acuerdo con lo anterior, podemos decir que la experiencia es un estar en el ahora, vivir consciente del momento, para que luego se reflexiona dando sentido a su existencia. Si el individuo logra desarrollar la interacción existencial desde la Terapia Existencial de Artes Expresivas se permite elaborar una realidad integrada de acciones comprometidas y conscientes a valorar; lo cual valorar es bueno para la persona y de ese modo llegar al proceso creativo a través del juego.

En las etapas de la Terapia Existencial de Artes Expresivas (TEAE) Mayorga-González propone tres etapas basados en Artes expresivas. En las cuales el proceso creativo se encuentra en la primer etapa llamada construcción del mundo terapéutico, que consiste primeramente en el despliegue de la imaginación este elemento se expresa a través de las modalidades sensoriales en la lúdica y las artes. El segundo elemento 
es la actitud frente al cambio, lo que permite acciones responsables en pro de la vivencia autentica de quien lo trabaje. El último elemento es la expresión y la imaginación a través del juego.

Como resumen Poiesis se puede comprender desde la concepción de que el conocimiento no es un hecho de pensar sino un acto de hacer (Mayorga-González, 2016). La Poiesis le da forma y sentido al mundo desde el proceso creativo a través del juego. Para que la Poiesis se dé, se desarrollan diferentes contextos a partir del juego de tal modo se promueve el contacto propio en los diferentes ambientes, de esta manera se propicia la libertad de expresión.

En la Poiesis trabaja con el proceso creativo (explorar experimentar y expresar) en estos espacios se promueve el juego no predeterminados para cada integrante, sino que se interactúa y se va descubriendo de acuerdo a las modalidades de las experiencias que van viviendo, logrando llevar a las personas a descentralizarse.

\section{Descentralizando la experiencia y cristalizando la posibilidad de cambio}

La existencia se va construyendo a partir de los relatos situacionales y relacionales que va presentando la persona. Las situaciones que se presentan van confrontando al sujeto y por el afán de la época, la reflexión se restringe y se va automatizando comportamientos y se busca evadir cualquier responsabilidad de las posiciones y acciones personales, esto se debe además porque las relaciones son inestables y generan ambientes inseguros y de cierre, lo que implica que en el encuentro terapéutico se debe dar un salto de fe, para lograr salir de ese modo restrictivo de existir y para ello se requiere un proceso de descentralización y cristalización.

La descentralización actúa como una extensión del autodistanciamiento, lo que permite salirse de la situación, monitorearla desde afuera y ver en ellas nuevas posibilidades de actuar, para ello se vuelve importante las modalidades de la imaginación, dado que con ellas la experiencia vivida puede transformarse en un juego entre la imaginación y la fantasía y entrar al juego de actuar en el proceso creativo.

Todo lo anterior, logra generar un proceso de cristalizar, de trascender la propia situación trabajada, generando no solo posibilidades de asumir posición, sino percibir 


\section{2}

las posibilidades más valiosas para disfrutar, cambiar o soportar las situaciones que se han explorado, experimentado y expresado.

\section{La actitud del terapeuta: la experimentación pobre y la experiencia sentida.}

Con la descentralización y la cristalización el proceso del encuentro terapéutico, implica una actitud del terapeuta en la relación con el consultante, a partir de esto, la disponibilidad intima, es decir, el cuidado, la apertura y reponsividad de la intimidad (aquello oculto, sagrado y misterioso) del consultante, lo que implica una respuesta empática, una conciencia de la experiencia del otro y un ambiente seguro y de apertura, que permita la exploración, comprensión y reflexión de la propia existencia y de la situación que enmarca el interés del consultante.

Cuando el consultante empieza a verbalizar su propia experiencia lo hace en términos de relación con su mundo, los otros y sí mismo, y puede llevar su situación a dos formas de comprensión, por un lado la situación como problema, lo que lleva a buscar una solución a la misma y esto generara mayor restricción a la reflexión, y más búsqueda de "sentirse-bien" psicofisicamente, generando un bucle entre maestarbienestar, esto se materializa en su relación de forma violenta, en competencia y en engaño de su propia frustración.

En el encuentro terapéutico el consultante llaga presentando una experiencia restringida y por ende percibiendo sus relaciones desde ambientes inseguros y de cierre, la situación se convierte en un nudo y su propia vida en un enredo, parte del ejercicio del terapeuta es lograr general descentralización de esta vivencia y llevarla a través de las modalidades de la imaginación a ver la situación, ya no como problema, sino como misterio, en esta forma de comprender la situación implica comprometerse con la propia vivencia, es decir con la propia existencia y sus dilemas.

La situación como problema se busca resolver solucionando los desafíos y tareas cotidianas, pero como misterio se busca reflexionar sobre los dilemas existenciales presentes en esos dilemas y tareas, pero para ello el consultante debe lograr distanciarse de su búsqueda de bienestar psicofísico y lograr trascenderse en la curiosidad y el asombro, para ello el terapeuta debe abrirse a una actitud fenomenológica, permitiendo colocar sus prejuicios entre paréntesis, conectándose 
con la verbalización de la experiencia del otro y su propia vivencia del aquí y ahora, para ello se vuelve de importancia la experiencia sentida.

La experiencia sentida o resonancia emocional que el terapeuta logra en el encuentro con el otro, logrando poner en manifiesto aquello que se a restringido y utilizarlo como un canal de cristalización y reflexión de la existencia, para ello se trabaja no solo con las modalidades de la experiencia, sino con la experimentación pobre, es decir, trabajar con lo que se tiene en el presente y eso en primera instancia es el yo como cuerpo y emociones, en segunda instancia materiales del ambiente y en tercera herramientas especializadas si las hay en el momento.

Todo este proceso, para permitir al consultante encontrarse con sus nudos y así trabajar con ellos y lograr encontrar en ese proceso la posibilidad de sentido presente en todas las situaciones.

\section{Conclusiones}

A partir de lo anterior, la Terapia Existencial de Artes Expresivas, busca tomar las bases de la logoterapia, la fenomenología, la experimentación pobre, para lograr acompañar al consultante a explorar y comprender la existencia como un continuo y complejo misterio relacional, que requiere ser reflexionado constantemente, para asumir la vida con apropiación y responsabilidad.

Parte de lograr acompañar al consultante implica consolidar junto con el un ambiente seguro y de apertura, lo cual es un espacio donde el consultante se sienta reconocido por sus actos, con oportunidad para desarrollarse y cuidado en la propia intimidad que busca expresar, en este espacio se da el encuentro terapéutico, donde se logrará intercambio dialógico autentico y colaborativo.

En la exploración comprensión y reflexión del misterio relacional, surge la oportunidad de distanciarse a través de la imaginación y la expresión de la propia experiencia, es decir del contenido narrativo de sí mismo, del otro, del mundo y de la situación. La Terapia Existencial de Artes Expresivas se convierte en una estrategia que, a partir de recursos imaginativos, creativos y la utilización de los propios recursos personales logra desenredar los nudos de la propia vivencia,

Es una invitación a desnudarse hacia el encuentro de las propias capacidades personales y el núcleo sano de la persona a través el puente que representan las 


\section{4}

modalidades de la imaginación presentes en la vida cotidiana pero poco explorada, comprendida y reflexionada.

\section{Referencias}

Castro, C. (2000). Vacío existencial en estudiantes de la UCAB. Caracas Venezuela. Academia. Recuperado de https://www.academia.edu/12567454/El_Vac\%C3\%ADo_Existencial_en_Estudi antes_Universitarios

Croquevielle, M y Traverso, G. (2011). El análisis existencial de Alfried Längle. La conducta en una vida con aprobación y consentimiento. Bogotá, Colombia. Academia. Recuperado de https://www.academia.edu/4831873/El_an\%C3\%A 1 lisis_existencial_de_Alfried _L\%C3\%A4ngle_La_conducta_en_una_vida_con_aprobaci\%C3\%B3n_y_conse ntimiento

Frankl, V. (1984). Tres grupos de valores para el sentido. Yucatán, México. Logoforo Recuperado de https://logoforo.com/tres-grupos-de-valores-para-el-sentido/

Grotowski, J. (1992) Hacia Un Teatro Pobre. México. Siglo veintiuno editores. Recuperado de https://monoskop.org/images/5/5f/Grotowski_Jerzy_Hacia_un_teatro_pobre_ 1992.pdf

Knill, P. (2009). Sobre las Artes Expresivas. Barcelona, España. TAE Barcelona. Recuperado de https://taebarcelona.org/artes-expresivas/

Kwee J, Längle A (2013) La Fenomenología en la Práctica Psicoterapéutica: Una Introducción al Análisis Existencial Personal (AEP). Recuperado de http://episjournal.com/journal-2013/phenomenology-in-psychotherapeuticpraxis

Längle, A. (2009). La Emocionalidad en el Análisis Existencial. Santiago de Chile. Instituto Chileno de Análisis Existencial (ICAE-GLE). Recuperado de https://www.icae.cl/wpcontent/uploads/2017/10/emociones_aboizard_icae_final.pdf

Längle, A. (2009). El análisis existencial de Alfried Längle. Santiago de Chile. Académica. Recuperado de 
https://www.academia.edu/31013558/El_an\%C3\%A 1 lisis_existencial_de_Alfrie d_L\%C3\%A4ngle

Lythgoe, E. (2014): El papel de la imaginación en La memoria, la historia, el olvido de Paul Ricœur. México. SciELO. Recuperado de http://www.scielo.org.mx/scielo.php?script=sci_arttext\&pid=S018524502014000200004

Martuccelli, D. (2010). La individuación y el trabajo de los individuos. Sao Pablo, Brasil. SciELO. Recuperado de: http://www.scielo.br/pdf/ep/v36nspe/v36nspea07

Mayorga-Gonzalez \& Talero Stephany. (2011). Interacción Centrada en el Sentido (ICS). Bogotá, Colombia Análisis existencial Colombia. Recuperado de https://docs.google.com/document/d/18qfmw7kRYImY9z_GwojlOZ4wbjkkw2 KySz7RD8BGUPw/edit

Mayorga-Gonzalez. (2014) Terapia Existencial de Artes Expresivas (TEAE) en desarrollo humano. Bogotá, Colombia. Asociación de Análisis Existencial de Colombia, Corporación Universitaria Minuto de Dios y Siendo Humanos Centro de Bienestar Existencial. Recuperado de https://docs.google.com/document/d/1 r5gfm l o9BkgP9WpGtp5f-CvUWVph3mt5Z_76ckSPUU/edit

Mayorga-Gonzalez. (2014). Interacción Existencial un enfoque vivencial expresivo basado en la Logoterapia IV Congreso de Logoterapia y Análisis Existencial. Bogotá, Colombia. Academia. Recuperado de: https://www.academia.edu/8651453/Interacci\%C3\%B3n_Existencial_un_enfo que_vivencial_expresivo_basado_en_la_Logoterapia

Mayorga-Gonzalez. (2015). Interacción, Drama y Existencia. Análisis Existencial desde las Artes Expresivas en Contexto. Bogotá, Colombia. Recuperado de: https://docs.google.com/document/d/1xDRddZWLfGCmNBFdXfObP-8ITZz_OCD4PsIBgacE3U/edit

Mayorga-Gonzalez, M. (2016) Estudios expresivos y existenciales de la vida cotidiana. Bogotá, Colombia. Editorial academia española Mayorga-Gonzalez, M. (2019) Logoterapia para la vida: Reflexiones para una existencia plena. Editorial autoreseditores 2019. Academia. Recuperado de: 


\section{6}

https://www.academia.edu/41920189/LOGOTERAPIA_PARA_LA_VIDA_Reflexi ones_para_una_existencia_plena

Meza, J. (2019). Imaginación. EcuRed. Bogotá, Colombia. Academia Recuperado de https://www.ecured.cu/index.php?title=Imaginaci\%C3\%B3n\&oldid=3520887. Modernell, P. (1967). Laing, el referente del movimiento anti psiquiátrico. Santiago de Chile. Psicocode. Recuperado de https://psicocode.com/psicologia/r-dlaing-referente-movimiento-antipsiquiatrico/

Stolorow, R.D. y Atwood, G.E. (2004). Los contextos del ser. Las bases intersubjetivas de la vida psíquica. Madrid, España. Aperturas psicoanalíticas. Recuperado de: http://www.aperturas.org/articulo.php?articulo=0000318

Telma, A. Pacífico, L. (2004). La concepción del arte según Vigotski y su influencia en la educación/educación física. Brasil. Dialnet. Recuperado de https://dialnet.unirioja.es/servlet/articulo? codigo $=5204860$ 